\title{
Combating Urban Hazard: A Qualitative Study on the Perception on Disaster Preparedness of STEM Students
}

Sean Erick Go

Laurianne Lim

Judyliza Cañete

LJ Gallera

RM Parone

Regelle Josol

Trexie Dapun

Jhudiel Dalagan

Alexandra Lancita

March 2019

Correspondence:

Regelle Josol

Team Leader

University of Immaculate Conception

Annex Campus

Bonifacio St., Davao City 8000

Davao del Sur, Philippines

(082) 2271573

(082) 2273794 


\begin{abstract}
In this study, the researcher identifies to what extent of knowledge does the respondents, STEM students of University of Immaculate Conception, know about Disaster Preparedness. This study spreads awareness to each individual to be more knowledgeable in a way of facing different calamites and disasters. In this matter, the knowledge of the respondents is being tested for their implication from what they have learned from the subject, Disaster Readiness and Risk Reduction (DRRR). In accordance to that, this would help them to be more educated regarding the said issue.

The researchers conducted a Focus Group discussion (FGD) and an In-depth Interview (IDI). The gathered data from the interview with the targeted participants was then transcribed and translated by the researchers. Among the answers given by the said respondents, the researchers have evaluated their prior knowledge about the said topic. The transcription was then analyzed and showed results.
\end{abstract}

Keyword: disaster preparedness, awareness, STEM students, DRRR. 


\section{INTRODUCTION}

\section{Background of the Study}

As stated by The American National Red Cross (2019), disasters ravaged millions of lives. The growth of the population, climate change, and urbanization are the mutilated live conditions for people in communities that are highly at risk and vulnerable to disasters and infectious diseases. Disasters amalgamated the consequences of poverty and inequity while eroding costly development gains. Eighty-five percent of those exposed to disasters dwelled in developing countries (United Nations Development Programme, 2013). Actions were taken to prevent the publicity of existence, assets, social and business activities, and commonplace resources from a natural hazard, along with mitigations, are essential to the awareness, education, preparation, and caution systems can reduce the demanding impacts of a natural disaster on groups. Improvement trends in the United States highlight the need to disseminate a brand new obligation to mitigation. In society, advances in the fields of hazard and danger assessment are providing decision-makers with progressively accurate and proper instruction on the possible impacts of the natural disaster. New alertness and education programs need to be established to promote incorporation of the lessons discovered from calamity and the information from social research into mitigation exercise. (The National Academies Press,1991).

In the world at risk of climate-related disasters, the Philippines is one of the top countries. The Philippines is a country with a high vulnerability to natural hazards. According to the International Bank for Reconstruction and Development (2014), the Philippines ranked third out of 173 countries vulnerable to disaster risks. This assessment was being based on the potential of a natural hazard to induce damage to infrastructures and properties, cause enormous human casualties, and decline of mortal welfare, such as livelihoods and health status (Tuladhar et al., 2015). The country is also vulnerable to the effects of climate change aside from the impact of disaster risks (World Bank, 2014). The geographical location of the Philippines is one of the factors why it is a disaster-prone country (Llanto, 2011). It is prone 
to geological and natural disasters such as earthquakes and volcanic eruptions due to its archipelago located in the Pacific Ring of Fire (Blanco, 2015). The country's location is also highly vulnerable to numerous meteorological hazards. (Lapidez et al., 2015).

It is located in the path of tropical cyclones, that were categorized as a tropical depression, tropical storm, severe tropical storm, typhoon, and super typhoon. According to Philippine Atmospheric, Geophysical, and Astronomical Services Administration, there is an average of 20 tropical cyclones entering the Philippine area of responsibility. The Philippine government has allocated crucial resources to establish disaster capacity and degrade population vulnerability and exposure, locally and nationally.

Some of the schools in Davao City are conducting a Disaster Preparedness Activity to help each student on what to do in terms of any upcoming calamities. According to Mac Mamon (2017), the Department of Education (DepEd) implements one of the contingency of the Philippine Disaster Risk Reduction and Management act of 2010 (DRRM Act) to promote this activity preparedness in the school curriculums and any other school programs, and to boost the level of resiliency of the students toward natural disasters. The City Government of Davao established the Central 911 on 2004 in performing the mitigation process needed for the city. They built 911 buildings and bought vehicles in fulfilling the readiness against suburban hazards. Furthermore, the City was recognized as the best government emergency management system (Sunstar Davao, 2018).

Previous studies that pertained to disaster preparedness focused on the Disaster Risk Reduction and Management of Tarlac City, its disaster risk reduction and management structure (Mohammed, 2018). The author of the said study also stated that the CDRRMO has a hazard map with identified barangays prone to flooding, lahar flow, an earthquake. The plans of the City Government are aligned with the Sendai Framework for Disaster Risk Reduction, and is evident in the list of programs and projects in their action plans. The existence of community-based responders showed that the City Government had extended support to the barangay level by molding local officials on how to respond in times of disaster. 
(Mohammed, 2018). Another study by Hoffmann \& Muttarak (2017) shows the Education and Experience Impacts on Disaster Preparedness in two countries, mainly in the Philippines and Thailand. On the contrary, the edge of this study regarding disaster preparedness despite the existing studies is that this research highlights the evaluation and assessment of what the STEM students have learned and how they could contribute on the mitigation process while being prepared from the disasters.

Unanticipated events such as disaster can inundate the capacity of the affected people to manage its impact. Numerous people are exposed to natural disasters in their life periodically; most disasters cannot be prevented (Kulatunga, 2017). Knowing how prepared the SHS students of UIC is, in times of calamities that could occur, assess the mitigation approaches they implement starting from themselves. Thus, this is a strong indication of the urgency and prioritization needed for this research's topic in lined with disaster preparedness.

\section{Purpose of the Study}

The purpose of this qualitative phenomenological study is to prepare, equip, further educate and serve as a warning to the respondents about what they could do for them to help mitigate the viable effects of a disaster and to recover with ease afterward. Also, another purpose of this research is to know the prior knowledge of the young citizens that could help not just themselves but also those who need assistance in time of the occurrences of the disaster. This research apprises the STEM students of the University of the Immaculate Conception about the importance of surpassing circumstances during disaster occurrence. The researchers accumulated data from the aimed respondents who have and have not yet experienced disaster and how they will utilize their premier understanding from their DRRR subject on any catastrophic activities that may transpire in the future. 


\section{Research Questions}

The aim of this study, in risk reduction planning upon fighting against the risks that urban hazards might cause requires the cooperation of the whole community and that includes households and schools within the community. This study aims to identify the implementation of policies that the University of the Immaculate Conception extends to be part of utilizing Disaster Readiness and Risk Reduction (DRRR), as well as to determine the impact of implementing such policies in managing and limiting risks.

Specifically, this attempts to answer the following questions:

1.To what extent the University of the Immaculate Conception plays an active role in limiting the risks of its students from Urban Hazards?

2. What is the perception of STEM students on their vulnerability to urban hazards?

3. How preparedness for hazards in urban settings can be improved?

\section{Theoretical Lens}

Numerous theories such as the theory of Planned Behavior and Disaster Preparedness, the Vested Interested Theory and Disaster Preparedness, and the Social Capital Theory that was connected in this qualitative phenomenological study, concerned into probing the preparedness among the STEM students of University of the Immaculate Conception in times of disaster. They are all highly applicable for this research because they contributed to the probable principles behind the behavioral approach of the respondents into answering the questions during the interview. 


\section{The Progression of Vulnerability}

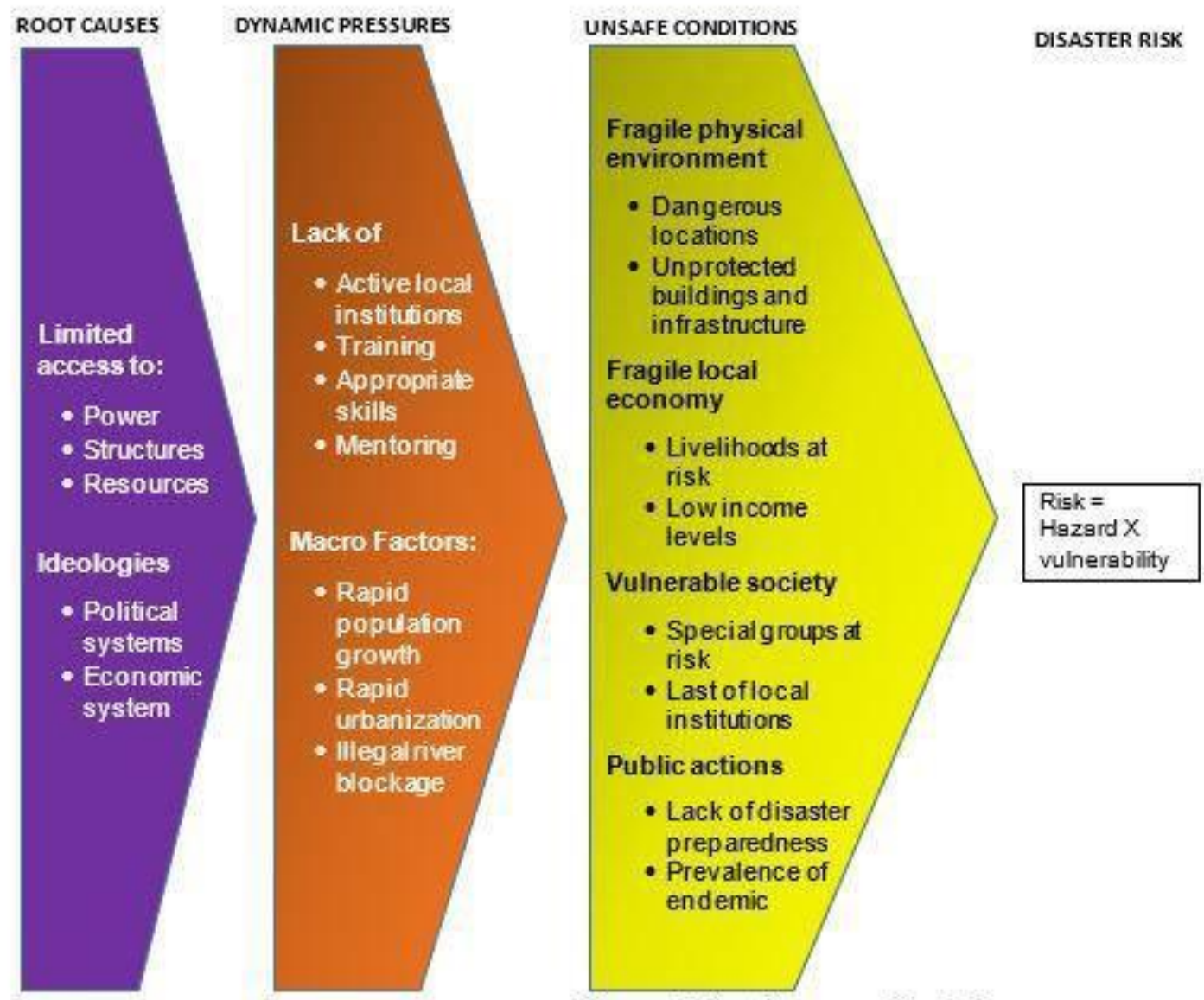

Figure 5. The Pressure Model

The main and the leading theory of this research was the Theory of Planned Behavior and Disaster Preparedness that was authored by Najafi et al. (2017). The Theory of Planned Behavior and Disaster Preparedness stated that disaster readiness, outlined as actions, guaranteed resources necessary to hold out an efficient response and were offered before a disaster, or they were obtained promptly once required. It was also the preparation and changes executed like storing food and water, getting ready a unit emergency set up, associate degree emergency kit, and alternative activities that alleviate the occurrence of risk and or injury. Disaster preparedness needed radical understanding of the factors that influenced performance or carelessness of disaster readiness behaviors. 

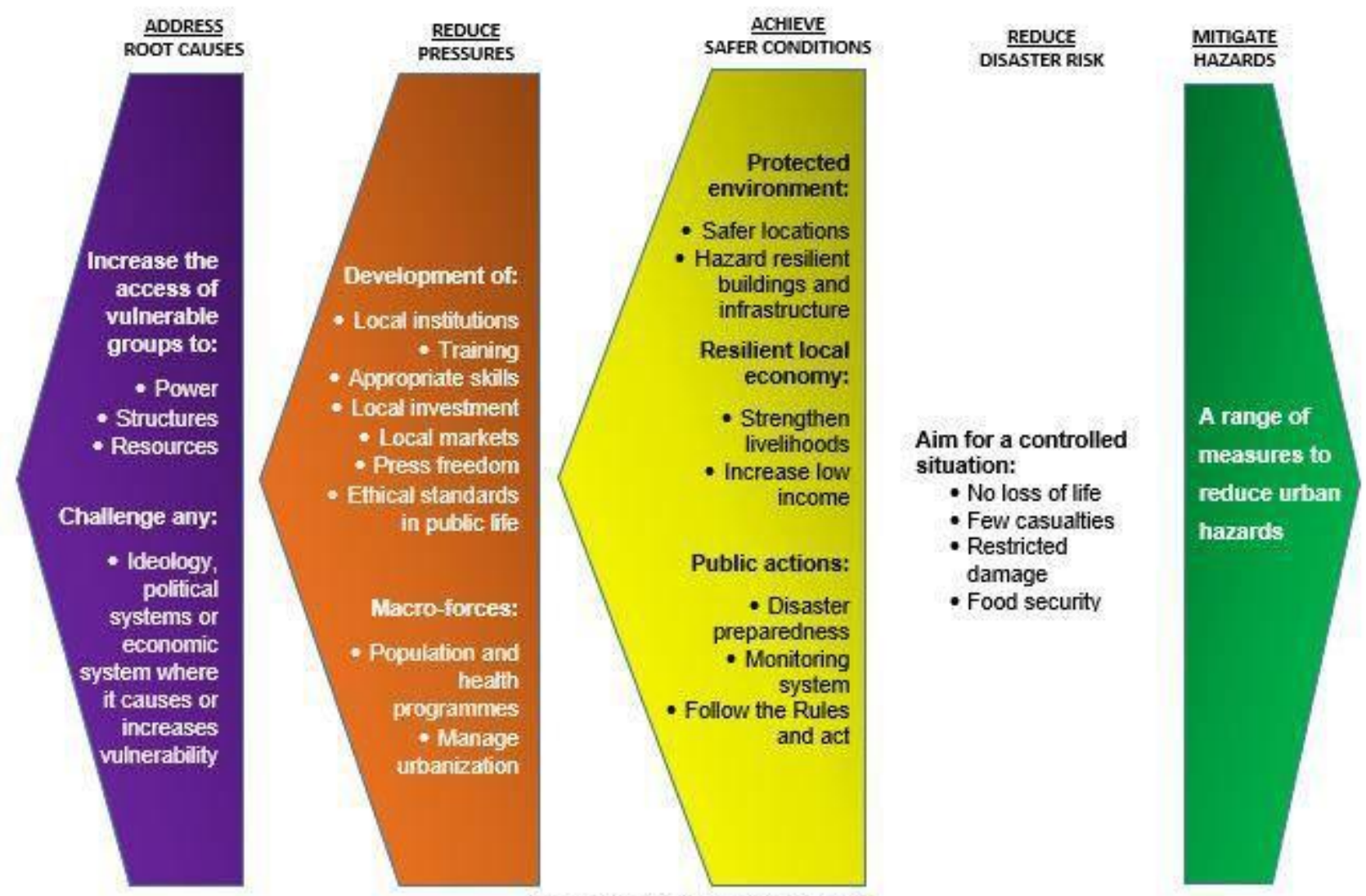

Figure 6. The Release Model

Another equally important theory was the Vested Interested theory and Disaster Preparedness that was proffered by Miller et al. (2013). It articulated the awareness relevance to disaster preparedness and the typical preparedness behaviors in every disaster. The Vested Interested theory and Disaster Preparedness also discusses the importance of managing hazards to gain a better understanding. This theory presents a lesson on what should be done before, during and after the disaster. This theory also explained the importance of awareness, engaged preparedness and the state of being always informed by making an emergency plan earlier individually or with other people involved. The Vested Interested theory and Disaster Preparedness; therefore, stated that being prepared is critical for all possible risk that may happen in a disaster. 
Furthermore, another theory entitled, the Social Capital Theory, was also deemed as one of the appropriate theories for this study (Kolanchu, 2011). This study was motivated to encourage individuals or groups to involve in determining and solving conflicts. Essential components of disaster risk reduction included education and awareness of people. It allowed individuals to engage in responsible decision-making upon acquiring the skills and knowledge to empower communities or people who are at risk (Nielsen \& Lidstone 1998). The said theory was linked to public awareness whereas it seeks to prepare individuals for joint efforts upon dealing with emergencies related to disaster risks. According to Babb (2005), the Social Capital Theory (Kolanchu, 2012) also promoted valuing diversity in others and similar life opportunities and a sense of belonging.

Henceforth, these three theories connected with the research issue of this qualitative phenomenological study.

\section{Review of Related Literature}

This chapter proposed a synthesis of research by the Qualitative study of the Disaster Preparedness of STEM Students of the University of the Immaculate Conception. Comprised in this chapter are the actions that STEM students can incorporate in preparation for possible upcoming disasters as well.

\section{Laws Pertaining Disaster Preparedness}

As constituted by the Republic Act No. 10121, known as the "Philippine Disaster Risk Reduction and Management Act of 2010", reinforces the disaster risk reduction and management system, allocating for the national level and its management framework, and establishing the National Disaster Risk Reduction and Management Plan, seizing funds herewith and for other initiatives. This Act bestows for the enhancement of policies, and the 
execution of activities and means concerning to all factors of disaster risk reduction management, containing proper governance, assessment of risks and early warning, minimizing the underlying constituents of danger and risk, and preparedness for successful response and fast recuperation.

The National Disaster Risk Reduction and Management Plan (NDRRMP) satisfies the prerequisite of RA No. 10121 of 2010, which gives the legitimate premise to strategies, plans, and projects to manage debacles. The NDRRMP covers four topical territories, to be specific, (1) Disaster Prevention and Mitigation; (2) Disaster Preparedness; (3) Disaster Response; and (4) Disaster Rehabilitation and Recovery, which compare to the structure of the National Disaster Risk Reduction and Management Council (NDRRMC). By law, the Office of Civil Defense details and actualizes the NDRRMP and guarantees that the physical system, social, monetary and ecological plans of networks, urban areas, districts, and regions are reliable with such arrangement.

As stated in section 16 of the 1987 Philippine Constitution, the State shall secure and advance the right of the people to equilibrium and beneficial ecology in accord with the harmony of nature. The creation of the Republic Act (R.A.) No. 9729 also known as the Climate Change Act of 2009 was built upon in this statement. The law which was implemented on July 27,2009 , was fundamentally formulated as the country's response to the worldwide phenomenon on climate change. The R.A. No. 9729 permitted mainstreaming of climate change into government formulation of projects and programs, agendas and strategies, and policies, formulation of Climate Change Commission, and initiation of Framework Strategy and Program for climate change upon approaching the fulfillment of this goal.

To mainstream Climate Change into Government Policy Formulation. R.A. 9729 is to guarantee that government actions and agendas are established upon sustainable 
development and environmental considerations. It calls for the state to assimilate the concept of climate change in different phases of policy implementation, poverty reduction scheme, development plans, and other government development tools and techniques.

The Climate Change Act serves as a policy that lays out the strategies, capabilities, and projects to prepare the country to the predetermined effects of climate change. Both the adaptation strategies and identified mitigation are pursued to build a more climate-risk resilient in the Philippines. Henceforth, as imposed in R.A. 9729 fulfilling the objectives of the plans are considered attainable with the assistance and support of all stakeholders which includes the local and national government units, the NGOs, the private sectors, and the local communities. In this study, as stated by the Community Associations Institute (2019), it is important to foster a sense of caring for the community, and as neighbors that come together to prepare and recover. This will provide information on disaster preparedness, resources of disaster victims and advice for homeowners to help smoothen the process of recovery. It also informs on what to do before a disaster to minimize the losses for individuals, and families should also develop an emergency plan.

An act to promote environmental awareness through environmental education and other purposes is the "National Environmental Awareness and Education Act of 2008". This policy of the state protects and advances the rights of the people to balance a healthful ecology, and to give special treatment to our nature like planting of trees or clean and green project, the vital role of the youth in nation, and the role of educators in sharing patriotism and nationalism for each and every one. This policy promotes total human liberation, and also promotes national awareness and the importance of environmental conservation and ecological balance. 


\section{Organizations and Initiatives created to strengthen Disaster Preparedness}

Creation of Climate Change Commission (CCC) developed as the lead policy-making body on concerns related to climate change as it is a linked agency to the Office of the President. The CCC is assigned to systemize, implement, and administer and assess programs and actions on climate change. Essentially, the CCC's greatest goal is to conceive the National Framework Strategy on Climate Change which shall serve as the foundation in formulating and establishing programs on climate change planning, research, and development (R\&D), and monitoring of activities. Furthermore, the CCC supports capacity building activities and provides technical and financial assistance extended to agencies and institutions.

The National Framework Strategy on Climate Change (NFSCC) was implemented to provide as the master plan for national programs and agendas towards more climate the risk-resilient Philippines. Establishing the adaptive capacity of communities, inducing the resilience of natural ecosystems to climate change, and optimizing mitigation opportunities towards sustainable development is its central goal. NFSCC serves as the foundation for the creation of climate change action plans both at the local and national level as a principle.

The NDRRMP is predictable with the National Disaster Risk Reduction and Management Framework (NDRRMF), which fills in as "the key manual for catastrophe chance decrease and the executives (DRRM) endeavors to the nation...." The Framework imagines a nation of "more secure, versatile and debacle strong Filipino people group toward reasonable advancement." It passes on a change in perspective from responsive to proactive DRRM wherein people have expanded their mindfulness and comprehension of DRRM, with the end in prospect of expanding individuals' strength and diminishing their vulnerabilities. 
The National Climate Change Action Plan (NCCAP) was developed to outline the proposed strategy under the NFSCC. It served as the lead of the municipal and city governments in drafting their relative Local Climate Change Action Plans (LCCAP), streaming down to the local units. The integration of climate change notion and encouragement of participation and cooperation of involved units and agencies are promoted in all levels of agendas and actions.

Community Associations Institute (CAI) supports communities and residents affected by all the recent natural disasters. They are working with Members of Congress and advocating for equal access for federal disaster benefits, give community association access to the federal disaster response funds and give us leadership in ensuring disaster relief fairness for the community association.

DEPED, TESDA, and other relevant agencies shall integrate environmental education whether in private or public school. Environmental education shall include environmental concepts and principles, international and local best practices, impact on human wellbeing, the responsibility of citizenry, the value of conservation, protection, and rehabilitation of natural resources. It covers also the activities, programs, and projects including tree planting, waste segregation, recycling, forest management, economic benefits, and other programs to provide implementations of different environmental protection law, to protect us especially our nature. We should be responsible for every practice because we are the one who makes our earth miserable. In every year the month of November shall be known as "Environmental Awareness Month "The relevant agencies shall lead the implementation of public education and awareness programs on environmental protection and conservation at all levels.

The Department of Environmental and Natural Resources (DENR) shall have the primary responsibility of informing all agencies concerned on current environmental updates 
including providing advice on environmental education activities the relevant agencies and barangay shall ensure that the information is disseminated to the subjects. DENR shall also undertake programs nationwide such us trainings, seminars, a workshop on environmental education. This will help us to prepare and be mindful in every disaster.

Even though it is significant for local governments and jurisdictions to enforce mitigation and planning measures before an emergency or disaster occurs, for the benefit of everyone, plenty of means should also be implemented ardently by the individual owners of historic properties, neighborhood, and local communities (Ready, 2019).

\section{Disaster Preparedness within Perspectives}

According to the IFRC Disaster Response and Preparedness (2019), disaster preparedness addresses the means conducted to reduce and prepare for the outcomes of

disasters via forecasting the possibilities, avoiding disasters and dangers it could be brought forth, mitigate and minimize the aftermath on highly risked locations and populations that are vulnerable, and responding effectively on dealing and surviving its consequences. Other than that, disaster preparedness offers a platform to plot realistic, coordinated and effective planning, decreasing the duplication of efforts, and increasing the overall efficacy of the household and the community's response efforts. Its pursuit implanted with risk reduction programs results in rescuing more lives and livelihoods upon the occurrence of disasters and empowering the distressed population to attain normalcy within a short span of time. But it also has to be kept in mind that it needs a continually integrated procedure to ensure and develop a massive range of risk reduction programs. Thus, it necessitates the contribution from several factors, like healthcare, logistics, and training, livelihood, recovery and institutional development

As stated by Ferry (2017), disaster preparedness refers to the preventive measures taken to decrease the worst effect of the disaster. The aim of disaster preparedness helps 
to reduce the impact disaster on vulnerable populations, to settle the institution for the influx of activity, and to make a plan that can decrease the waste of resources, time and efforts. Disaster preparedness can save the huge number of lives and property caused by the disaster, and as quickly as possible the effect of normalcy of population should be returned is the aim of disaster preparedness.

According to Smith (2019), disasters have an effect on hundreds of thousands of humans every year on a personal, business, local community or national level. The golden rule for successful catastrophe administration at all stages is to increase awareness, boost actions plans and exercise them. Waiting for a catastrophe to take vicinity is no longer the right time to plan. Communicating and constructing relationships with those around you, whether or not they make a contribution actively to the diagram or are structured on it, will have the hugest and fantastic effect in determining your resiliency throughout an event. Here are some actions to keep in mind when planning to mitigate disaster and assets to assist preparedness.

Disasters strike in each and every corner of the world, in the course of each season, and on one-of-a-kind scales during the year. Non-profit agencies serve as key players throughout these disasters, imparting useful resource and assets to those affected. Indeed, hospitals, food banks, human and animal shelters, and other non-profits are integrated into most response and restoration efforts throughout emergencies. These activities are frequently unexpected by their very nature, leaving little time, if any, to prepare. That is why it is necessary to give time for planning and long preparation before the disaster strikes.

Disaster risk is an indicator of poor development, so reducing disaster risk requires integrating DRR policy and DRM practice into sustainable development goals. Historically, dealing with disasters focused on emergency response, but towards the end of the 20th 
century it was increasingly recognized that disasters are not natural (even if the associated hazard is) and that it is only by reducing and managing conditions of hazard, exposure, and vulnerability that we can prevent losses and alleviate the impacts of disasters. Since we cannot reduce the severity of natural hazards, the main opportunity for reducing risk lies in reducing vulnerability and exposure. Reducing these two components of risk requires identifying and reducing the underlying drivers of risk, which are particularly related to poor economic and urban development choices and practice, degradation of the environment, poverty and inequality and climate change, which create and exacerbate conditions of hazard, exposure, and vulnerability. Addressing these underlying risk drivers will reduce disaster risk, lessen the impacts of climate change and, consequently, maintain the sustainability of development.

According to Community Disaster Preparedness and Relief, $\$ 1.7$ trillion in damage, 2.9 billion affected and 102 billion killed. Community Associations Institute (CAI) encourages all associations to help, and also teach on how our community can plan, prepare, rebuild and recover from any type of disaster. No matter what type of disaster occurs in the community, one should be prepared to oversee. The key components of every community's natural disaster preparedness plan should include the advance planning and drill recovery and restoration and some activity that is connected to the disaster preparedness. Having a complete disaster plan is crucial for community resiliency and sustainability. Identifying hazards and assess vulnerability is one of the types of mitigation activity that helps to reduce infrastructure damage and disaster impact.

Figuring this situation in out ahead of time can make things so much easier in a difficult situation. The Red Cross deliver that using an out-of-area emergency contact to have family members check in with since it might be easier to make long distance calls. It should be that everyone has a list of emergency contact and local emergency phone numbers. Sign up for 
emergency alerts and know how officials will communicate during a disaster. They can get these on their phone if they have not disabled them already. Knowing that blaring noise is to catch up the silent mode in the phone can be annoying, but this is the best way to learn emergencies if they are constantly attached in their phone. The emergency alert system is also a broadcasts over the radio, television, and NOAA weather radio it tells severe weather expected 24 hours a day, seven a weak. It will pop out in social media as well, but do not expect to rely on it exclusively as they may keep their internet connection in an emergency.

The mission of the University of Missouri System four-campus data administration software is to set up the criteria for retention of data to ensure the university retains the imperative statistics to meet legal, financial, administrative, research, and historic needs and to furnish an efficient types administration program for the orderly gathering and processing of university statistics in the most budget-friendly manner.

According to Aquino et al. (2014), climate change is the most crucial and prevalent threat interfacing humanity today. The highest scientific body accountable for assessing the risk of climate change, the Intergovernmental Panel, declared that the warming of the earth's surface is unambiguous. If unconstrained, the impacts of climate change on humanity and the environment are unparalleled and will steadily affect the lives of future generations.

\section{Measures Taken in Preparing from Disasters}

The following measures that individuals are required to do before a disaster strikes are to be prepared; get trained; identify, evaluate and document resources; register qualified resources; prepare emergency preservation and recovery plans, and integrate preservation planning with general planning. First, you must compile a list of fundamental emergency 
contacts, decide which agency or what person is accountable for what activities and make the information widespread and available. Sustain enough emergency supplies. Second, emergency responders must be befittingly trained and should know what to do during the disaster to be prepared to assist their neighbors and help secure property and most especially, protect lives. Third, resources must be first identified, evaluated and documented and these are necessary for disaster preparedness planning that makes local surveys essential for this step. Fourth, register qualified resources and the pre-disaster listing is vital in how the expedient is treated when remarkable damage is induced as a result of a disaster and will guarantee a proper evaluation in any administrative process influencing the resource which includes the factoring of probable repair costs. Fifth, distinguish risks and evaluate vulnerability to prepare emergency preservation and recovery plans. Execute mitigation work and pre-disaster rehabilitation to deduce possible impacts to properties. Put funds aside, adopt disaster decrees, and instigate strategies and stimulant programs to facilitate recovery efforts. Lastly, develop local stimulant programs to manage the security of resources through incorporating preservation planning with general planning.

Disaster Preparedness Planning. Upon being posed with significant threats to its historical and cultural properties due to disasters including floods, fires, earthquakes, other natural and man-made disasters that could potentially devastate property within the state, the Office of Historic Preservation of California has provided guidelines in which helps individuals to know what to do before a disaster strikes. Being prepared by observing the risks, foreseeing them, and being thoroughly prepared before, during, and after a debacle could indicate the difference between the total depletion of a resource and restraining the resulting damage.

Events that occur like a natural disaster, being prepared by conducting a preparedness plan can be an evaluative element that helps secure a safe conversion out of hazard for you, your family, your loved ones and properties. Preparation is the key, but being calm and focused during a disaster is also essential. If you are told to evacuate, follow and 
do so. If you are not evacuating, use your time to prepare the important documents and things that you will need to survive for the next two or three days.

Be ready at home and workplace. Prepare, plan and practice. These three factors are important for the individuals and the families to gain knowledge, increase their awareness, get educated, and to have a broad understanding to prepare for the worst effect of hazards. And also, as an employee, you should make sure that your working place has an emergency and evacuation plan. You should always sure that your contact with local authorities and emergency hotline will stay to know what to do and to be informed for some announcements about what is happenings.

Know your community's vulnerabilities and the agencies can help you plan. Know the types of disasters that mostly affect your location will help you to avoid the worst effects of that disaster and also help you to make a plan. Being connected to the local agencies that reported the happening of your location will become a big help for your planning. These agencies can help you to be aware of.

Youth preparedness. Youth have a big role in the community, the total coordination, the perseverance, to be one of the big contributions in some preparedness. Nowadays I observe that the youth want to involved in youth voluntary team in this personal endeavors to help others especially the victims and survivors. Youth is highly involved in this preparation like for instance preparing the relief goods and to transport the relief to such pilot affected area. Youth preparedness is one way to have a way of positive thinking that they rescue, help and have more educate into how to make this disaster have a good output in the result.

Landslide Debris Flow. Landslide is the breakdown of soil due to the heavy rains that can make the soil soften. Due to it many materials like masses of rock and other debris move 
down a slope. Landslide problems are commonly experienced in the coastal area. Before landslide, you should avoid passing through nearly by drainages, and to the places that prone to landslide accident. During landslide, stay alert and awake, listen to the information and instructions of the authorities. After the landslide, go to a safe place or to the evacuation center. Stay updated to the news about the disaster.

Power outages. When a disaster happens it would have a result of any problem of electrical wirings that caused a blackout and to avoid an accident in the result of blackout they need to use necessary tool or materials such as flashlights or safety kit before this disaster happen, it should be prepared all these things for emergency cases. And you should save energies as well.

Make and practice your plan. Make a disaster preparedness plan with your family so that you are prepared in terms of any disaster that you may encounter. Besides being prepared this plan helps you to have knowledge on what to do during the disaster. After this, you should practice your plan by applying it in a real-life situation. By this, it can help you to lessen the number of accidents that may cause death. Having a family preparedness plan can help the family members' safety and far from dangers.

Financial preparedness. This financial preparedness is able to realize the one people to be ready and have financial availability when the time of disaster, trouble, an unexpected scenario. Some of the barangay officials and leaders prepare some of the forecasting report or financial analyzation to make an immediate service of money to provide all of the necessary needed in the disaster.

Earthquake. A violent movement of part of the earth crust. It will happen without warning, and if an earthquake happens, first you need to protect yourself. Find a secure 
place and do not run outside. When an earthquake threatens, earlier you need to prepare safety kits such as flashlights, enough food, water medicines, and as much as possible create a family emergency communication plan that has an out of state contact you have the plan where to meet if you are getting separated. You can consider obtaining earthquake insurance. This will help if you have collapsed during the earthquake restructure the house/ building. During an earthquake, cover your head and neck with your arms. Hold or go under the strong furniture until the shaking stops. Do not run outside.

Be safe after. Aftershock is followed, check yourself for injuries and provide assistance to others if you have training. Quickly move away from the building. If you are trapped inside in the building, make a send a message or create a sound so that the rescuer finds you.

Prepare to be Prepared. Disaster prevention is first and foremost about preparation. Pre-plan every job before employees begin any work. Schedule a meeting or huddle with all participating employees to fully understand and outline the details of the job and ensure each employee understands what they are required to do. Provide detailed instructions and when necessary, offer information in additional languages to ensure employee understanding. The best approach involves outlining the scope of work, key issues, potential problems, equipment access, personnel access, and any other relevant information.

Be Informed. After preparation, the next disaster prevention measure is knowledge. Make sure the physical and chemical characteristics of hazardous substances are visibly listed and can be clearly seen and read by all employees. These lists should include items such as boiling and freezing points, density, vapor pressure, specific gravity, solubility, volatility and the product's general appearance and odor. 
Get Supplies Ready. It is not pleasant or fun to think about a potential spill, but if it does happen, they will be glad they prepared the necessary supplies to clean it up. These supplies include containers, temporary diking and cleanup materials. Make sure to have the highest quality equipment and store all necessary equipment in the proper areas that are easily accessible in the event of a spill.

Personal Protective Equipment. Review the PPE and tools that are necessary for the project. Make sure your supplies of these materials including clothing, helmets, masks, goggles, etc. are adequate and in working order. Perform a thorough review of your equipment to ensure nothing is outdated or worn down, as these deficiencies can cause injuries. Communication is key for most challenges in life, but especially for disaster prevention. Before work commences on a project, analyze how the work will impact other personnel and operations. Then, make sure the proper communication channels and procedures are in place between participating parties. Double Check. This isn't a before-thejob measure, but it's still preventive. Plan time for a final walk-through to be sure nothing is left behind or unfinished when the work is complete. The Department of Homeland Security, the Red Cross, the Centers for Disease Control and Prevention and many other organizations have a wealth of information on the topic. To keep things simple, we sectarian it down.

Know what to look forward to. The first part of preparation is to know exactly what kind of calamities that might occur and what action should be needed to learn what to do in each stratum. Learn the evacuation routes and shelter locations. The time to figure out these things is not while a hurricane is a linkage down at the community. After a tsunami alarm has been announced. Evacuations are actually common; it will serve to know well the details in time. People should always know to avoid artery from their own home, include more clear one, like out that ground-level in their window bathroom. If they have kids better, they draw 
a map and post it near the door. They should always be ready to plan where their family to evacuate when the disaster come. Decide ahead of time where would go in case of emergency and it is better to go in Red Cross shelter. Know how to reconnect with people who matter. Not a valid communication plan. If networks are not working, they do not need to worry about how their Netflix stream will be affected. Consider how they will contact their family or their roommates.

Conduct risk assessment and inform your plan with a statistic. Identify the potential hazards and effects of this to know what kind of plan you may use and follow through with action and mitigate risks. The need for systematic data for disaster mitigation and prevention is an increasing concern for both development and response agencies. In the past, data needs were addressed on an ad hoc basis, which included collecting the information at the time of the emergency. However, there is growing importance and understanding that data collection, analysis, and management can help both short and long-term development goals and help to identify and address disaster risks.

Learn what to do if they are caught away from home. Obviously, if they are not in their home when disaster strikes. In the case of an unexpected emergency, they should always be prepared to react from different locations to avoid nonplussed, include their workplace or in a car. The most basic way to do is know their evacuation routes, communication plan and how they will receive an emergency message. Always have a plan to connect with kids who may be at school. They need to know or talk to the school if they will communicate the families in terms of the disaster come or they have a sheltered place plan or where they go if they need to evacuate. Have a kit and know how to use it, when disaster comes food, water, first aid, and other emergency equipment that they might have already. Include the flashlight and duct tape the key to assembled and ready to use, not scattered all over their 
house. Make sure that everything is work and that no one sneak snacks from their finished kit. Especially the first they have in their kit is the can goods which is easy open can but if they do not know how to do it or use it all of that is useless

Keep in mind people who may need special preparation. Kids, disabled people, a senior citizen may all need special considerations while planning for an emergency. If one of the family members need medication or special equipment, they need to plan and sure bring them with always. Talk to the neighbors to being as one and talk them about how to help each one another when disaster come and check always each one another in case of emergency. Prepare for the pets. The goal of emergency preparedness is to keep the whole family safe and includes pets. If people need to evacuate, they should never leave their pet because animals have feelings too.

Try to evacuate to friend or relatives house if ever pets or animals are not allowed inside the public shelters. Keep an emergency kit on hand for a pet include foods and important items. The ASPCA recommends microchipping pets so they can easily have identified and returned it without tags so the owner can invest in a GPS tracker so they can find them on their own. The ASPCA app also helps us to track the pets at the emergency shelter and it is helpful tips for a variety of situations.

Learn emergency skills that can always come in hand. Make sure to know little things that can solve a problem, like how to use a fire extinguisher or perform a basic first aid. Trained in a CPR or the even simple hands CPR, which is can save someone's life even not expected. They also need to learn how to shut off utilities in their house in case of emergency. Find out how to help the community during a disaster. Volunteer fire-fighters are trained to 
respond to all of the emergency. As a human, they need to learn and possibly be a community leader during a disaster or teach others to prepare. Volunteer positions with local emergency response agencies or nonprofits are available in a huge range of capacities.

The main factors in guaranteeing that historic properties are appropriately discerned, assessed, and managed promptly after a disaster happens and in the recovery period subsequently are vital preparedness planning and mitigation. There are essential steps taken before a tragedy might occur though it may be unpredictable to minimize the risk of damage. It is everyone's responsibility to prepare for disasters.

Flood. It is overflowing water onto land that is normally dry. The result from the heavy rains, storm surges, and overflow od some water systems. If you are under flood warning; Find safe shelter right away. Do not swim or drive through flood waters. Because if you have wounds or cuts it might harm yourself from the bacteria found at the floods water. Listen to the emergency alerts. If the volume of water becomes higher go to the higher place for safety. But before that, you should have to prepare emergency kits such as foods, batteries, clothes, important documents, and some other important things to bring. Survive during, you should go to a safe location. If the authority told you to evacuate, do so immediately. Then if you are in the Evacuation center stay inside, do not go outside to avoid injuries. Be safe after, you should listen to the information and instructions given by the authorities. Return home if the authorities say it is safe to go home. If you are inside the house it has a big possibility that there are snakes and other animals left by the flood. You should wear heavy gloves and boots during clean-up. If the electrical outlets are wet, you should turn off the electricity to prevent electric shock. Because safety is the most important. Safety first! (Ready, 2019). 


\section{METHODOLOGY}

This chapter presents the methods that have been used in this study to investigate the Disaster Preparedness of STEM students of UIC.

\section{Research Design}

In this research study made use of a phenomenological approach to gather relevant data. According to Creswell (2007), a phenomenological study describes the meaning for several individuals of their lived experiences of a concept or a phenomenon. The researchers facilitated the qualitative research design by conducting In-depth interviews. The phenomenological approach concerns itself with understanding and interpreting the meaning that participants give to their everyday lives (De Vos, 1998). The qualitative approach focuses on the qualities of human behavior (Ferreira et al., 1988). This paper assessed the extant research and practice of resilience and disaster preparedness in the Philippines, which serves as a good model on how to strengthen resilience and promote disaster risk reduction at the local level (Alcayne, 2016).

In this study, the qualitative approach is appropriate for this study because the data collected and used focuses on the participants' subjective experiences on the process of disclosure and the way they interpret them. With this study, they could easily assess the relevance and withheld on what really matters on this certain topic.

\section{Sampling Method}

Snowballing, which is a non-probability sampling method was used to draw up a sample of participants who provided acceptable information for the study. Snowballing 
sampling is a method whereby the researcher starts with one member of a group who in turn refers the researcher to another member (De Vos, 1988; McClure, 2001.) Although the researcher was referred to

participants, the researcher selected participants who were recognized to be information rich and appropriate for the study. The researchers tried to assemble a sample of people from diverse backgrounds in order to get more varied data.

\section{Participants}

After prospective participants were identified, the researchers approached and invited them to participate in the study. They were presented with the information sheet and were further informed their right to refuse participation and that participation was voluntary. When they agreed to participate, they were also made aware of their right to withdraw from partaking in the interview. They were further informed that the information that they provided in the interviews would also be treated with confidentiality, they were not required to disclose their identifying details. They were presented with consent forms for their participation and for the audio tape recording that they signed to give their consent. The participants consisted of two girls and three boys which are grade 11 and grade 12 STEM students respectively. All of the participants shared and presented their knowledge about this study.

\section{Research Instrument}

In this phenomenological study, the research questions were well prepared by the researchers. The questions will be examined first with the assessment and validation process, conducted by the validator, Mr. Joseph Dave M. Pregoner. After the authorization, the questions will be pilot tested. The instrument which will be utilized in this qualitative phenomenological study is interview questions and will be recorded for authenticity 
proposes. The questions are written and asked in English and they can use the language that they are comfortable with in order for them to freely express themselves without uncertainty.

\section{Data Collection Method}

Data was collected using face to face focus group discussion interview schedule. According to Ferreira et al (1988), interviewing is the most important data collection instrument. The interview used is semi-structured, which is a list of questions and problems to be discussed that was prepared before the interview. The semi-structured interview gives a room for discerning

classification and further discussion of the essential and appropriate issues that appear during the interview. Where the basic questions were stated to fit the particular participant. Focus group discussion interview empower the researcher to obtain detailed information about personal and group feelings, perceptions and opinion from the discussed issue. The interview was audiotaped and later transcribed.

\section{Data Analysis Method}

The results were examined using thematic content analysis method. Braun and Clarke (2006) described this method as a way of organizing, identifying, reporting, analyzing and describing themes that are evident within the data set. They also argued that this should be a fundamental method for qualitative analysis as this method of analysis provides core skills for conducting many other forms of qualitative analysis. Boyatzis (1998) described thematic analysis as a translator for those speaking the languages of quantitative and qualitative analysis, allowing researchers who use different research methods to communicate with each other. Marshall and Rossman (1989) informed the steps used in establishing themes and included the following procedures. 


\section{Organizing data:}

The researchers repetitively read the transcribed data thoroughly to be familiar with the data.

\section{Generating categories, themes, and patterns:}

Supported by the integration of the assimilation of the results, the results then determined the most essential themes, patterns of belied and recurring outlooks. Analytical and creative thinking is required in this stage. Noting patterns in the research participants are involved in the process of generating categories. The researchers then searched for those categories of meaning that were internally consistent but discrete from each other as the said categories emerged. Categories, patterns, and themes were unveiled.

\section{Testing emergent hypotheses:}

The researchers then evaluated the credibility of the hypotheses that were developing and testing them against the data when the patterns and categories became evident in the data. Testing emergent hypotheses involved analyzing the data for their authenticity, sufficiency, centrality, and practicality.

Searching for alternative explanations:

The researchers engaged in challenging the patterns that seemed discernible as patterns and categories between them emerged in the data. Until the researchers attained the explanations that are most rational of all, alternative explanations were examined and described.

\section{Report the results:}

The researchers give shape, interpretation, and comprehension to the huge amounts of raw data by reporting the results report. 


\section{Trustworthiness of the Study}

Upon conducting this qualitative phenomenological study, the researchers distributed a letter to the five (5) participants. These letter comprised of an agreement that all of the information acquired was utilized solely for the purpose of the study and was handled with

utmost confidentiality. To ensure the trustworthiness of the study, credibility, transferability, dependability, and confirmability should be established in the research. The aim of trustworthiness in a qualitative inquiry is to support the argument that the findings are "worth paying attention to" (Lincoln \& Guba, 1985).

The researchers were confident in terms of the credibility of the result of this research paper since the five (5) participants are authentic Grade 11 and 12 students under the STEM strand of UIC. According to Devault (2018), credibility bestowed to a belief in the trustworthiness of data through the succeeding criteria: (a) prolonged engagement; (b) persistent observations; (c) triangulation; (d) referential adequacy; (e) peer debriefing; and (f) member checks. Transferability

does not include broad claims, but enticed readers of the research to make a union between elements of research and their own experience and will be substantiated by providing readers with evidence that the research study's findings could be useful to other contexts, situations, times, and populations (Universal Teacher, 2019). Also, according to Lincoln and Guba (1985), it was the level to which the findings of this inquiry can be transferred further outside the bounds of the project. To verify the transferability of findings, the researcher provided the sample site and description of the study. Dependability is to enhance the quality of data and preciseness of data findings as stated by Hammersley and Atkinson (1995). It was regarded with the reliability of the information over time with a need to be able to substantiate changes to the original text. To achieve dependability in this study, the study's participant validation was done with the teachers and all in authority to verify the result of the study. To establish conformability, the researchers demonstrated the other data collected in FGD and IDI in different ways through analysis procedures, and confidence of not tolerating any form of potential biases. The way of asking questions was addressed with the utmost respect. 
The researchers assure that whatever information gathered in this research are not fabricated and falsified. After transcribing their responses, the respondents reviewed and checked it and then they are asked to sign on the lower right portion if everything wrote was factual as a sign of authenticity. The researchers assured the respondents that their identities will be confidential.

\section{Ethical Consideration}

After the approached participants agreed to participate, informed consent was first sought from them. This was achieved by reading with the participants both informed consents of participation and tape-recording and asking them to sign in order to grant their consent. Participants were informed of the confidentiality clause. The researchers humbly asked the considerations and participation of the respondents for the researchers to have a successful gathering of data by recording all of their response after asking them questions. In line with this kind of participation, the researchers informed them about the confidentiality of our study. The State of New South Wales, Department of Education and Training (2009), states that confidentiality is the privacy of every individual's information. It also means that the information must be kept only between the researcher and the client. Therefore, the participants would not be bothered about keeping the information because the data collected stays between the researcher and the supervisor. Also, the identities of the respondents would be confidentially kept. All of the equipment used during the interview will be also kept in a safe place like tape-recorders. After the gathering of data and the study has been finished, all of the tapes will be destroyed.

\section{Role of the Researchers}

The researchers would perform the research procedure to achieve the organization and oneness of the study. The researchers were assured to be open-minded about the different sides of an argument and to avoid bias. The researchers were responsible for the 
direction and progress of the research and the delivery of the research paper in an appropriate standard of the relevant maximum time period.

The researchers also need to be a good timekeeper, and as believed, that research was done in a long period of time, but some of the research should be done in a limited time period only. And so, as the researchers who was only given a limited time, the researchers would manage their time to accomplish and finish all parts of the research before the deadline. The researchers would convey the cultivated reports from the FGD and IDI, proofread and check it for the formulation of an organized assessment. The researchers would encode and investigate the data that would be collected. And ultimately, the researchers should be responsible enough for the information they had gotten from the participants. Also, the researchers filtered the sensitive information they have collected in respect to their respondents. 


\section{RESULTS AND DISCUSSION}

This chapter has been formulated to answer the research question keeping the literature review and research findings from the interviews in consideration.

Research Question 1: To what extent the University of the Immaculate Conception play an active role in limiting the risks of its students from Urban Hazards?

The risk reduction planning and management in the Philippines was implemented by the national arena and the local government served as one of the key factors to fully realize the risk reduction practices. The participants viewed the interaction to be hierarchical, that is, communication about the management from the national state is passed through the local state of Davao City, and the local state passed the information to the school

As shown in the Venn diagram below, the national state and local state overlap each other and this area of overlapping was perceived by the participants to be the communication being made to enact the practices of risk reduction. The school adapted these practices set by the local government.

One participant urged:

"I believed that the local government is one of the vessels that informs the school about the standard practices of the government ... this is quite saddening because the school has no voice in the national arena to air out what the education sector really needs in terms of limiting the urban hazards." 


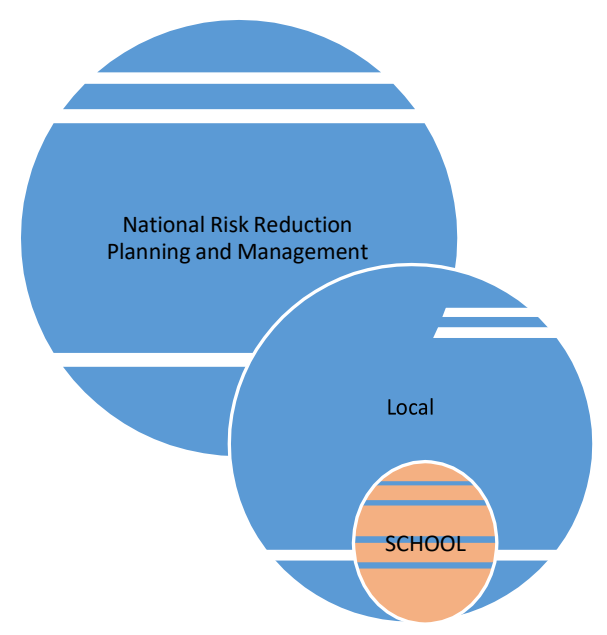

Figure 1. Venn diagram showing the role of the school in limiting urban hazards

As described in the previous quotation, the school's voice in limiting urban hazards particularly those that are occurring in the school is limited only because there is a gap between the national state which is making and implementing laws and practices and the school which is enacting the laws and practices to the students.

Research Question 2: What is the perception of STEM students on their vulnerability to urban hazards?

This research question employed a deductive approach in sorting the interview extracts. This is anchored by the Pressure Model analyzed by Hai and Smyth (2012). According to the model, a natural phenomenon by itself is not a disaster; similarly, a population can be vulnerable for many years, yet without the "trigger event", there is no disaster. Vulnerability to many extents can be connected to the socio-economic and political aspect including poverty, age-related discrimination, exclusion or exploitation based on 
gender, ethnic or religious factors, which requires to be addressed to reduce the risk of a disaster. The model further states that people become vulnerable when they are unable to anticipate, resist and recover from a hazard. Analysis of this research question was based on the three layers of social processes that cause vulnerability, they are: root causes, dynamic pressures and unsafe conditions (Hai \& Smyth, 2012:). The model gives a chance practitioners and policymakers to analyze, understand, react and plan accordingly to people's vulnerability to disasters.

\section{Root causes}

The participants identified the school had limited access to power and structures. These limitations were included in the root causes layer of the social processes that causes vulnerability because the participants perceived these restrictions as factors that increase risk hazard.

One participant mentioned:

"....when the school has restricted access to power ... structures ... if they don't really participate in risk reduction planning, the students are vulnerable."

The participants also mentioned that political systems played role in increasing vulnerability of the school. They urged that corruption impeded the services given by the local state to the educational sector to reduce the risks of urban hazards.

"... when you corrupt ... you are cutting the services ... these must be given to the people ... to the school."

\section{Dynamic pressures}

The lack of active local institutions was also perceived by the participants to be the factor for them to become vulnerable to the risks of urban hazards. One participant asserted:

"I really think we [Davao City] had weak implementation of risk reduction practices because our local government is not really geared toward preventing earthquakes, floods, etc." 
Another participant urged that the lack of proper trainings was also a factor that increases vulnerability of the school inhabitants. She believed that appropriate skills must be needed in order to spread the awareness about risk reduction.

She mentioned:

"How can we implement those practices if the students, as well as the school, are not properly trained."

\section{Unsafe conditions}

The last layer pertains to the conditions of the school's infrastructures that could increase vulnerability to urban hazards. The participants mentioned that the physical environment of the school had unprotected buildings and infrastructure. They believed that the school could easily be affected by the urban hazards because they perceived this to be fragile physically.

One participant held this in view:

"We are in the fault line I believe ... so this greatly affects our risks for earthquakes."

Research Question 3: How preparedness for hazards in urban settings can be improved?

On the issue of earthquake, the participants mentioned that the experts are saying that compared to the housing patterns and construction materials used in the buildings that collapsed in other countries, it is stronger in the school. However, the lack of knowledge of the participants in limiting the risk would pose significant drawbacks during the urban hazard. Thus, in addition to structural development, at the moment, the participants mentioned that concentrations should be given to non-structural issues like awareness building and advocacy for the students, preparation for the mitigation in case of major disaster, strong monitoring tools, equip the service providers with modernized equipment, training for increasing the efficiency of the fire fighters and volunteers in the school. 
One of the participants mentioned a crucial point. As all the skilled firefighters are mostly based in Davao City, in case of a calamity the probability of they being affected is quite high. Thus, the participants mentioned that several organizations should be taking initiative to include, train and increase human resource for fighting urban hazards like building collapse, fire accidents, and earthquakes from areas surrounding the school.

One participant urged:

"We should address the root causes like the government itself should increase access of the school to structures, power ...the school should be equipped with the trainings to acquire skills in reducing urban hazards."

Another participant mentioned:

"The school should coordinate with the national state to improve the practices. How could the state make programs if they don't consider the education sector?" 


\section{CONCLUSION AND RECOMMENDATION}

This chapter presents the formulated conclusion based on the results gathered in this research, and followed by the recommendation of the researchers to their corresponding beneficiaries.

\section{Conclusion}

Conclusions are established in context of the three main sectors set in the primary chapter of the study. The following influencing factors are the national and local sector, as well as the sector pertaining the school.

The national and local government of the Philippines implemented a risk reduction planning and management as the local government passed the information to various schools and universities. The University of the Immaculate Conception, and other various institutions adapt the practices set by the local government. These practices may help them train or prepare the student in every disaster. The school should coordinate with the local government as this can inform the school about the announcements of the government in relation with disaster preparedness. The school applies this practices for the welfare of the personnel within, and most especially for the students.

According to the Pressure Model analyzed by Hai and Smyth (2012), disasters could also be included in the political aspect which pertains to corruption that can lead to poverty, discrimination, and the like. The model further states that people become vulnerable when they are unable to anticipate and overcome a hazard.

The respondents identified that the school had only limited supplies for disaster preparedness. These limitations were included on the social processes that cause vulnerability because the respondents recognize these restrictions as factors that increase risk hazard. 
Furthermore, infrastructural development is also considered as one of the contributing factors to prepare from disasters. In the end, the researchers found out that the sturdiness of the institution's structure that could withstand a catastrophe, could also result to safer outcomes.

Ultimately, the researchers also found out the importance of disaster preparedness education, such as the implementation of the subject DRRR, to the youth, like what the STEM students study as the said subject is part of their curriculum in their strand, to fully equip them with actions that they can perform in times of disasters.

\section{Recommendation}

Base on the outcomes and results of the research, the researchers would like to recommend the following:

- That the future researchers, should dig in deeper with the lapses in terms of the national sector in Disaster Preparedness, as they should have an effective communication to the schools as well, rather than just transferring solely the information to the local sectors and agencies for higher accuracy of information delivery about disaster preparedness from urban hazard and assemble more target participants for a higher range of effectivity of their future research.

- That the faculty and staff, as well as the institution, would adhere to the requests of the respondents of this research, in ensuring a safer campus' environment by providing more precautionary equipment and facilitating symposiums about disaster preparedness.

- That the parents, would check on the welfare of their children by preparing them from upcoming disasters and teaching them what to do during those circumstances.

- That the stem students, should evaluate and execute their learnings about disaster preparedness from their DRRR subject in times of disaster occurrence, and as they learned about it they should share this to other people as well. 


\section{References}

American Red Cross. (2016). APA style. Retrieved from https://www.redcross.org/aboutus/our-work/international-services/building-safer-communities.html

Alipio, M. (2020). Predicting Academic Performance of College Freshmen in the Philippines using Psychological Variables and Expectancy-Value Beliefs to Outcomes-Based Education: A Path Analysis. https://doi.org/10.35542/osf.io/pra6z

Alipio, M. (2020). Academic Adjustment and Performance among Filipino Freshmen College Students in the Health Sciences: Does Senior High School Strand Matter?. https://doi.org/10.35542/osf.io/xq4pk

Blanco DV. Disaster governance in the Philippines: Issues, lessons learned, and future directions in the Post-Yolanda super typhoon aftermath. Int J Public Admin 2015; 38:1-14. Available from:

http://www.academia.edu/13029525/Disaster_Governance_in_the_Philippines_Issu es_Lessons_Learned_and_Future_Directions_in_the_PostYolanda_Super_Typhoon_Aftermath.

Boyatzis, R. (1998). Qualitative Information: Thematic Analysis and Code Development, Sage Publications.

Braun, Virginia; Victoria Clarke (2006). "Using thematic analysis in psychology". Qualitative Research in Psychology.

Center for Innovation in Research and Teaching (n.d) Retrieved from https://cirt.gcu.edu/research/developmentresources/tutorials/ethics

International Bank for Reconstruction and Development/The World Bank. Community Mapping for Disaster Risk Reduction and Management: Harnessing Local Knowledge to Build Resilience; 2014. Available from: http://www.iapad.org/wpcontent/uploads/2015/07/Community-Mapping-for-Disaster-Risk-Reduction-andManagement.pdf 
Llanto GM. Mainstreaming disaster risk management in local governments. Policy Notes No. 2011-05. Philippine Institute for Developmental Studies; 2011.

Marshall, C,. \& Rossman, G. B. (1989). Designing qualitative research. Thousand Oaks, CA: SAGE Publications. 
National Disaster Risk Reduction and Management Plan (2011-2018) Retrieved from http://www.ndrrmc.gov.ph/attachments/article/41/NDRRM_Plan_2011-2028.pdf

National Institutes of Health. (n.d). APA style. Retrieve from https://www.ors.od.nih.gov/ser/dem/emergencyPrep/Pages/Disaster-PreparednessTips.aspx

Revita, Juliet C. (2018, May 29) Davao City flooded. Sunstar Davao

The International Federation of Red Cross and Red Crescent Societies. (2019). APA style. Retreived from https://media.ifrc.org/ifrc/what-we-do/disaster-and-crisismanagement/disaster-preparedness/

The Lawphil Project. (n.d). APA style. Retrieved from https://www.lawphil.net/statutes/repacts/ra2010/ra_10121_2010.html

Tuladhar G, Yatabe R, Dahal RK, Bhandary NP. Disaster risk reduction knowledge of local people in Nepal. Geoenvironmental Disasters 2015; 2:1-12. Available from: https://www.link.springer.com/content/pdf/10.1186\%2Fs40677-014-0011-4.pdf. 
